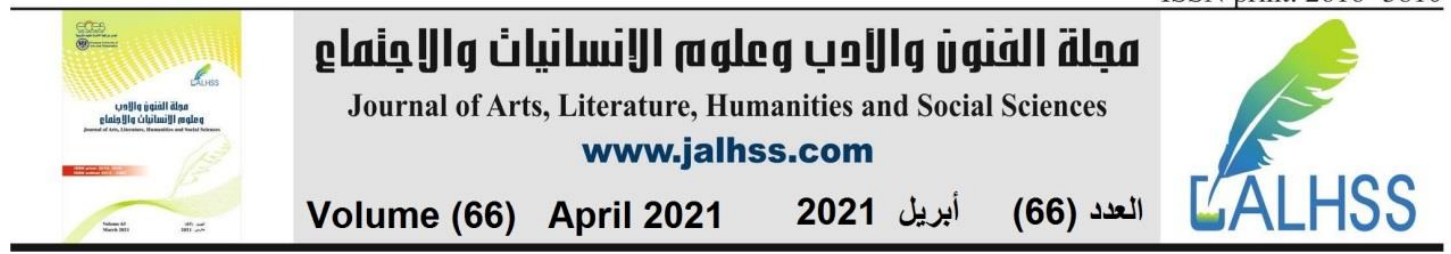

\title{
Enhancing the Role of Saudi Women in Community Development in Light of the Kingdom's 2030 Vision
}

\author{
Dr. Merfat Mohammed Mahdi Bassi \\ College of Art and Design - Jeddah University - Kingdom of Saudi Arabia \\ Email: Mer_bassi@yahoo.com, mmbassi@uj.edu.sa
}

\begin{abstract}
This paper focuses on the importance of the Kingdom of Saudi Arabia's Vision 2030 in strengthening the role of Saudi women through developing their social status and empowering them in various fields, including political, medical, educational, technical, health, scientific, and sports fields. This study sheds light on the social position of women in the figured world from different countries, especially in the Middle East, by answering the fundamental human question "who am I in the world" regarding women. After noting the obstacles that women are facing in their communities and how they suffer from being shaped by these obstacles, I demonstrate some possibilities for helping women to engage in a dialogue with their society as a way to understand themselves and help others understand what they want to be in the world. Some of these solutions involve women's engagement with different practices using artifacts, such as dancing, singing, creating artworks, and using their bodies to convey their message to other people in the world. In this paper, I present a personal visual reflection of how women struggle between two different worlds - East and West. One of my paintings reflects what women want to be in their world by giving them a space of freedom to express themselves without the restrictions that would prevent them from having positive interaction with their community. Finally, this paper describes the significant role of Vision 2030 in supporting Saudi women allowing them to author themselves in their community and providing them with many opportunities to build their society and contribute effectively to development and progress in various fields.
\end{abstract}

Keywords: Social position, figure world, Vision 2030, artifacts, identity. 


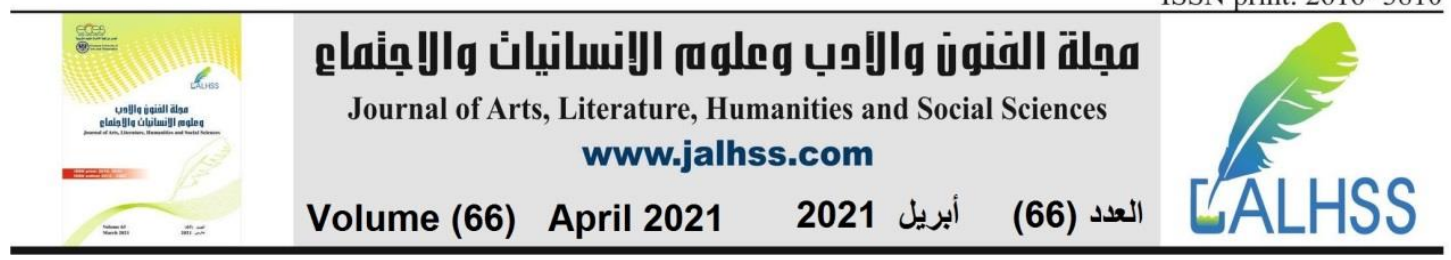

"Who am I in the world?" is a fundamental question that relates to our identity as we understand our social position in the society and recognize who we are in the whole world. Identity is a complicated concept that has multiple facets of various personal traits or characteristics. Our identity is confronted by real challenges of everyday experience in the various stages of our lives as well as environmental and cultural factors that combine together. Culture is an important factor that plays a significant role in shaping our positional identity. Holland, Lachicotte, Skinner, and Cain (1998) defined "culture" as a fundamental power inside us that guides our attitudes. Culture directs our understanding of how we value ourselves as well as other individuals in various social positions. Therefore, culture can divide us within dominant groups or minority groups depending on our races, genders, religions, and ethnicities, a situation which affects our relationship with others who are different from us.

The purpose of this study is to highlight the significant role of Saudi Vision 2030 in supporting Saudi women, providing a space for them in an alternative world, and shaping their social position by developing their identity in the figured world. In this paper, I first focus on women from different countries, especially in the Middle East, who are suffering at the hands of other individuals, particularly those from dominant groups who shape them in specific social positions. Next, this paper will provide different possibilities and solutions for helping women to make a space of dialogue as a kind of artifact to aid individuals in practicing their identity. Additionally, I will show some of my personal paintings as a kind of visual reflection of how woman struggle between two different worlds: East and West. Finally, I will demonstrate how Vision 2030 helps Saudi women to author themselves and face social and cultural constraints on their expression and the development of their identities.

\section{The Social Position of Women in the Figured World}

Culture determines our perspectives on understanding our own social positions as well as those of other individuals. Therefore, culture can guide us in various ways; for instance, it helps us understand our social positions in the figured worlds when others shape us to be in a specific position and vice versa. Holland et al. defined identity by stating, "Identities become important outcomes of participation in communities of practice in ways analogous to our notion that identities are formed in the process of participating in activities organized by figured worlds" (p. 57). Figured worlds highlight the identity of individuals by portraying the reality of their everyday life in the world.

Figured worlds reflect who women are in their communities by focusing on their actions, practices, and behaviors. For example, women from the Middle East practice their identity as wives and mothers who take care of their family by providing for their needs in everyday life. Women can use some tools or instruments that help them to engage in different life activities and practices. Holland et al. argue that artifacts, which serve as instruments with which individuals engage with their worlds, could 


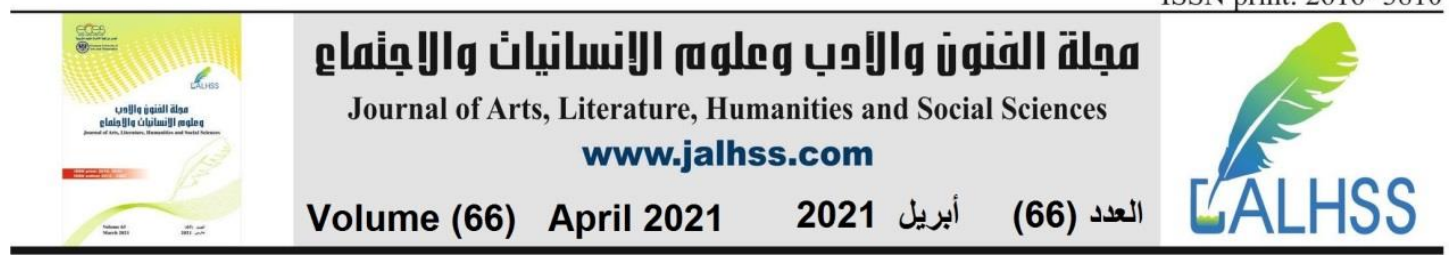

open up the figured worlds by helping individuals practice different everyday activities, actions, and performances.

By engaging with their figured worlds through using particular artifacts which help them to practice their different roles, women can understand who they are in their community and what their positional identities are. When individuals cannot understand their own identity and cannot explore the answer to the fundamental human question "who am I," they may face a problem of low self-confidence. Women should understand their social positions in their worlds; they should know what roles they have to play in order to be effective members in their communities.

Voloshinov (1929) presented an important view of individualistic confidence connected to the relationship between the individual and society. He wrote, "Individualistic confidence in oneself, one's sense of personal value, is drawn not from within, not from the depths of one's personality, but from the outside world" ( $p$. 89). I agree with Voloshinov that the feeling of confidence comes from outside ourselves, which means it comes from our world or the community that we interact with in everyday life, and they shape our social positions.

In the Middle East, for instance, women have a feeling of lowered confidence when they face various levels of discrimination against them and experience gender inequality in numerous areas, such as educational, economic, political, and social fields. Women do not have a variety of job opportunities similar to that available to men; they have more chances in the educational field than in other fields. Another example that illustrates the discrimination against women is unequal wages between individuals of different genders who are in the same position. Crenshaw (2015) discussed an important relationship between racial and gender discrimination, which was a critical problem in and of itself; however, for black women the consequences were compounded. Racial and gender discrimination overlapped not only in the workplace but in other arenas of life, as Crenshaw demonstrated.

Crenshaw defined the term intersectionality, which was born from the complex structure of anti-discrimination law. "Intersectionality is an analytic sensibility, a way of thinking about identity and its relationship to power," Crenshaw asserted (para. 5). As Crenshaw explained, intersectionality brought to light the important concept of the invisibility of groups that claim them as members but often fail to represent them. This happens with members of minority groups who face discrimination and bias from members of dominant groups who depict them as invisible because of their race, gender, ethnicity, and religion.

Here, I want to highlight more the important concept of social position, which is related to how people in different positions deal with each other; in many situations, this depends on their relationships and how close they are together. Holland et al. addressed the meaning of positional identities, which is that "positional identities have to do with the day-to-day and on-the-ground relations of power, deference and entitlement, social affiliation and distance - with the social-interactional, social relational structures of the lived world" (p. 127). For example, in the Middle East, the relationship between parent and daughter or husband and wife are limited 


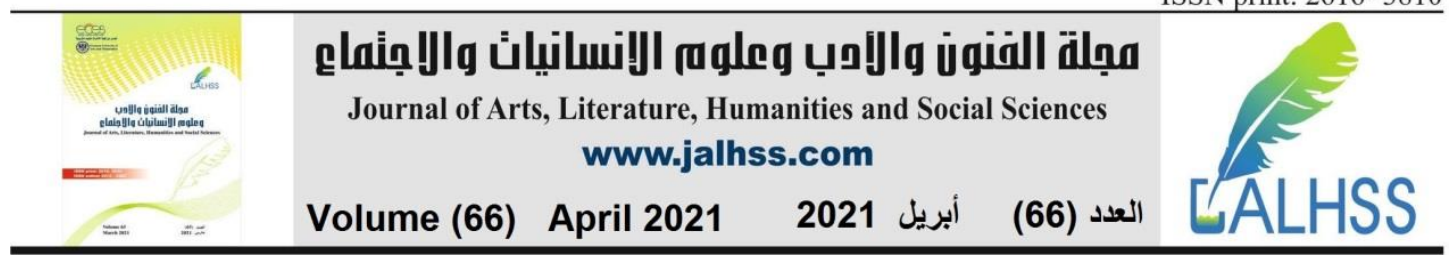

constructions which are formed by the dominant groups; the daughter or wife is not allowed to leave their house if she doesn't have permission from her parent or husband.

Holland et al. clarified the ways in which positional identities rely on actions, which create different relations of distance and hierarchy. For instance, in some of the closed or strict societies in the Middle East, the man has great authority to possess his wife's properties, while she has no right to ask them back from him. For this reason, women use deferential speech strategies when communicating with their husbands, or in general with men in the work arena, for example. Women have struggled to deal with the different positions and situations they encounter every day in her lives, which lead them to feel unequal with men.

Women can have this kind of feeling as a result of dealing with members of dominant groups, such as parents, brothers, husbands, and sons. Different cultures treat women differently, but they still look at women as members of a minority group. Therefore, women are still struggling to obtain more rights and have their voice heard in their community, especially in the Middle East. Holland et al. addressed cultural boundaries and the lack of privilege and power; according to them, "Culture forms are presumed to affect and shape subjectivity, and these culture forms come in great variety" (p. 26).

I believe that women from the Middle East understand their positional identity in their society when they see themselves in terms of a particular model or template. The perspective that women should be passive limits her role as an effective, contributing member of her community, an individual who is more than capable of helping to build her society just like a man. The roles society prescribes to members convey a significant message to the entire community as to who the important, valuable contributors and creates a positive relationship between those individuals and society. Holland et al. described the position of a woman in terms of "Her disposition - to see herself through the figured world and to recognize her vulnerability to insults to her attractiveness" (160). Women try to change this situation by refusing or accepting this position that others force them to be in even if they don't like it. According to Holland et al., the development of social position into a positional identity gives minority groups their right and voice: "Social positions, in other words, become dispositions through participation in, identification with, and development of expertise within the figured world" (p. 136). Women have to determine the position in which they want to be; they should be active in the figured world; they should have power to decide what positions are proper for them.

Holland et al. highlighted the important concept of dialogism as a kind of artifact to help individuals practice their positional identity. They clarified the figured world of dialogism as "one in which sentient beings always exist in a state of being 'addressed' and in the process of 'answering"' (p. 169). They gave a clear view of how receiving others' perspectives of self could create an understanding of selves and identities authoring the self - via the creation of a relationship with others through dialogical 


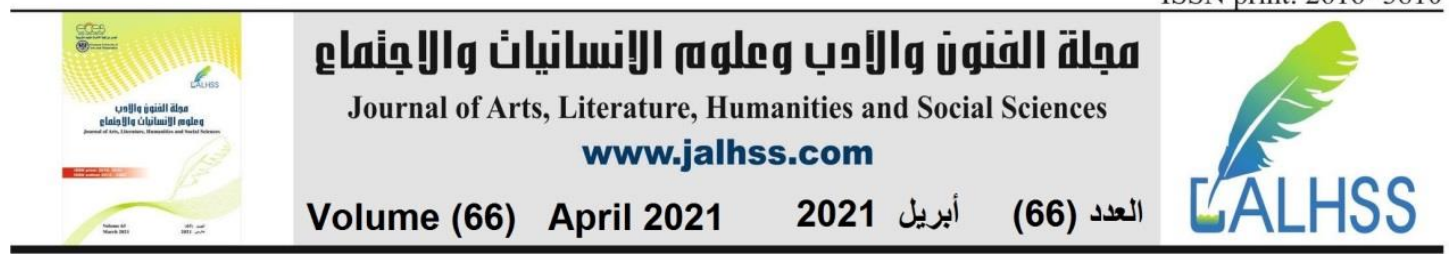

practices. Through others' eyes, we can understand who we are and form ourselves in our social positions.

In addition, women come to know their positions in society by understanding how others treat them, for example; until now women have struggled to obtain more rights and become equal with men. Holland et al. confirmed there are differences between inner speech and social speech, for instance, when women have a voice to share with society and appeal their rights to be responsible people without any authority from men, instead of staying silent. Holland et al. discussed the meaning of "space of authoring" which is a concept related to the zone of proximal development.

Women try to find a space for authoring themselves and conveying their message to the world so that they can develop their identity and express their social positions. Women can create a space to author themselves by using dialogue with others to develop their identity. The next goal of this paper is to explore different possibilities for women to engage in a dialogue with their society, to have a space for authoring themselves, and how these possibilities might help them to deal with social and cultural constraints.

\section{Possibilities for Women to Engage in a Dialogue with Their Society}

After discussing the social position of women in the figured world by focusing on some obstacles that have faced them, I now want to describe certain practices as solutions that might help women to demonstrate their existence in terms of being an effective part in their community. In particular, I want to give an example of the movement into positional identity associated with the good Hindu women. According to Holland et al., these women's complex and contested self-understanding developed and was produced through various activities. One of these activities was the Tij festival, a 'space of authoring' gendered identities, which opened up an imagined space where women envisioned and rehearsed a figured world that rearranged gender relations.

Clearly, the Tij festival provided a space for play and a time for women to engage in a dialogue with their society and to reflect upon their lives in domestic relations. Tij songs are a tool for authoring oneself as a woman in this society, which means a Tij song is an artifact for women to author their positions in the figured world. The songs provide a perspective on a woman's life, an understanding of herself as a female, as a subject not an object. In this way, women have expanded the scope of their agency or power in the world of domestic relations.

Holland et al. defined free play as "the form of activity that proceeds in ignorance of any constitutive condition other than a cultural and conventional design" (p. 236). Through playing and engaging in activities, we can open ourselves to different possibilities and imagine a new figured world to reshape ourselves. As Holland et al. confirmed, "The interplay of a person's identities is thus open to and dependent upon a field of continuing social discourse and everyday interaction" (p. 251). Thus, women author their social positions in the figured world by using different artifacts, 


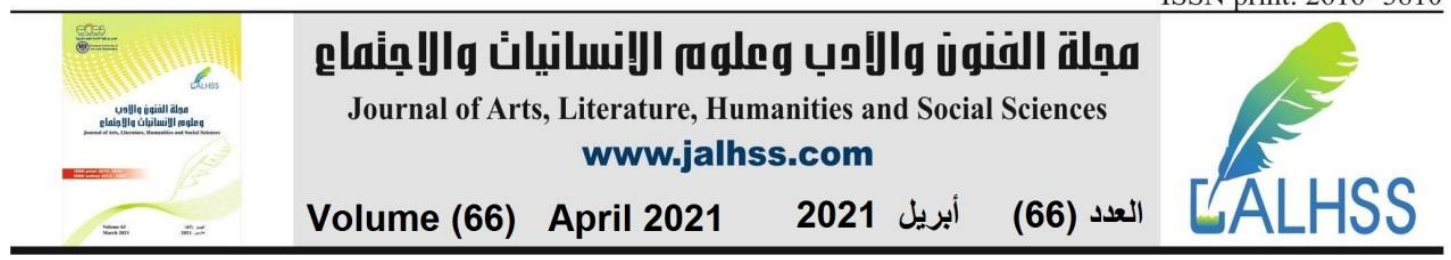

such as singing and dancing, making artworks, and using language to convey their messages to the world.

The next example of authoring a space for women to develop their social identity by engaging in a dialogue with society is the use of an artwork. In an interesting article, Dieudonne and Scherbael-Ball (2016), who assert that in some Arab countries, women must still ask permission from a man to get a passport, to travel and leave the country, or to marry. The authors asked three female cartoonists from North Africa to draw some images to express how the community and custom play a significant role in women's lives in their countries. Obviously, the use of this kind of artwork is a method to give women from the Middle East a free space by using different activities to author their identity.

Here, I wish to point out how certain artists deal with different issues that women encounter in their everyday lives. In Egypt, Doaa el-Adl creates various images that focus on the issue surrounding a trend for wealthy Gulf men to travel to impoverished Egyptian rural areas to find much younger temporary brides, who are girls who have just become of legal age for marriage in Egypt. In Tunisia, Nadia Khiari illustrates the continuing pressure on rape victims to marry their attackers in order to avoid bringing shame on their families. A third country is Morocco, in which Riham Elhour selected as a theme of her cartoons foreign travel and the numbers of Moroccan men who are using the law to stop their wives from travelling abroad.

Women in the Middle East aim to convey the inner speech of their thoughts into social speech via certain activities, such as creating a dialogue by making artworks as artifacts. These artifacts can be not just the artworks, but also the thoughts and the supplements, and also their body which make the artworks. In Nepal, women try to use their body as artifacts and move their bodies in a free space to imagine an alternative world that could give them the agency to develop their social identity.

In reading an article by Merino (2015), we can understand how art practices support females in expressing the social restraints placed on their gender - i.e., on the female body. Merino explores how four artists visually present in their ceramic work different nuances of Beauvoir's thesis on the social constructions of women's identity. All four artists employ surrealism to carve out an abstract intellectual space for the viewer to engage with their work. The body is the container in which our identities exist, but it is far more than just a physical container. Merino explores a significant concept, the relationship between the self and others, which focuses on how we personally identify ourselves and how we are identified by society.

As I have previously stated, women still struggle to gain their rights and voice, as demonstrated by the examples of women from Arab countries and from Nepal, so they must use different activities to convey their mission to the world. Women need to engage in a dialogue with others and find a space to author themselves. They have to perform different practices by using artifacts, such as dancing/singing, creating artworks, and using their bodies to convey their message to the world; the last is the next focus of this paper. 


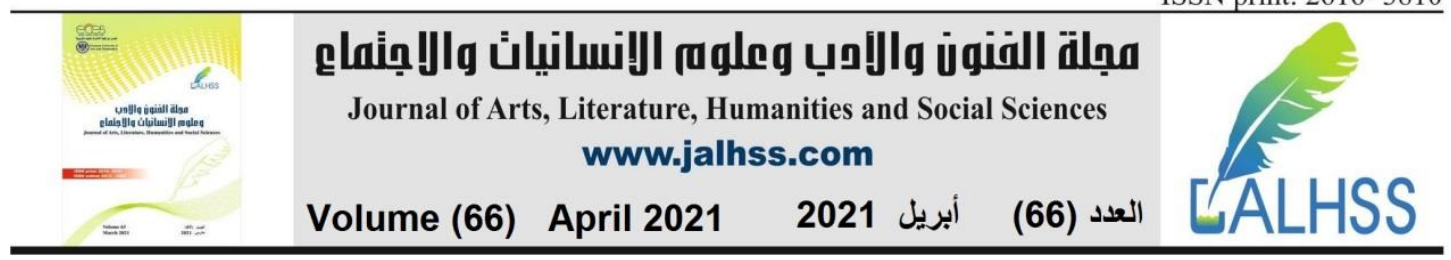

Women's use of their bodies to tell a story about themselves means engaging in a dialogue with others. Rowsell, Kress, and Street (2013) analyzed tattoos on subjects' bodies and approached the task from what they termed three optics; each optic illustrates how a woman constructs her identity through her body art. I am interested in the point that a woman can use body art as a key to her identity to illustrate her life with different visual narrative stories. Body art and/or tattoos are 'artifacts of identity;' viewing them as artifactual makes them materials carried through time and carrying memories. These narratives are related to our lived experience of engaging in practice in the world. We express ourselves by using narrative, which allows others to discern our social positions or identities through our personal speeches.

Our identities interact with other people in different ways, and we engage in our worlds and in a variety of activities or practice, which reveal who we are. According to Sfard and Prusak (2005), identities are like a gathering of tales or stories about individuals, which are endorsable, reifying, and significant. However, these narratives reflect the identity of a person and are significant factors in determining the actions of individuals and understanding who they are. Sfard and Prusak presented an important description of the actual identity and the designed identity. Both of these identities rely on reifying important stories about learners. When we talk about ourselves and define our identities, we use words - i.e., in the narrative method - to construct an understanding of who we are in the world.

Consequently, the goal of the previously discussed possibilities or solutions, which depends on making a place for women, is for women to author themselves in the figured world by using different methods. These methods/activities were the dancing and singing of Hindu women, illustrating cartoon artworks that focused on women from Arab countries, presenting ceramic work to express social restraints related to the gender issue, and using women's body art - tattoos - to tell a story of everyday lives. These solutions can help women to deal with social and cultural constraints in order to express and develop their identities. Women should understand that they are human beings, as subjects, interacting with their surrounding environment. They are not objects, which are guided by another dominant group. Women should try to find other possibilities to author themselves in the figured world and develop their social identities. In the next section of this article, I describe my artworks that portray a woman from the West and East and discuss how others recognize her from different perspectives. Also, in one of my paintings, I will show how a woman prefers to be without being force by others to author herself in the world. 


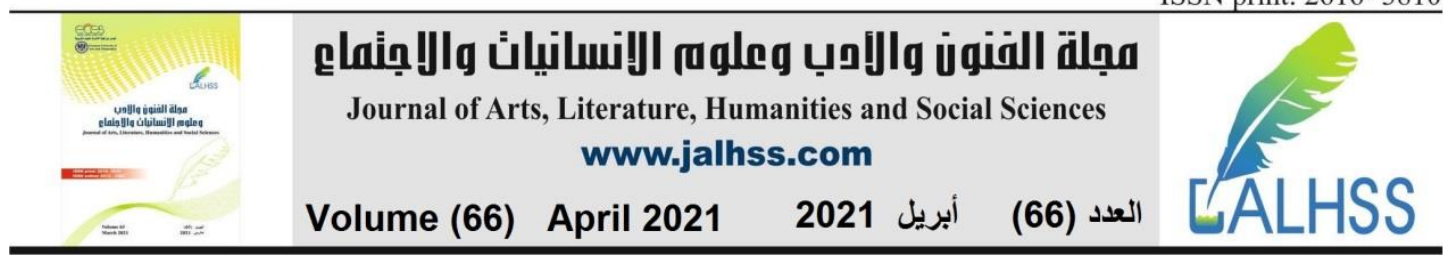

\section{Personal Visual Reflection: A Woman Between Two Different Worlds (West/East)}

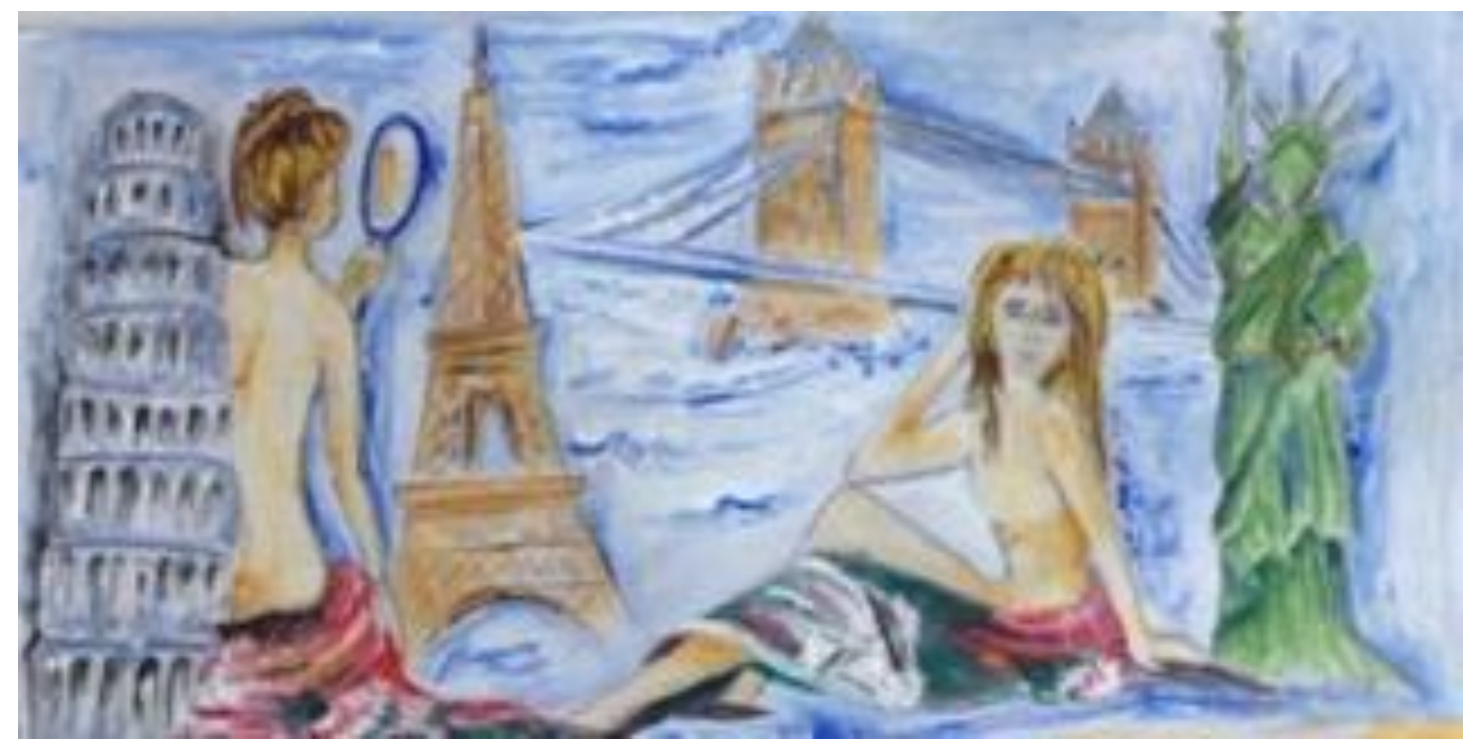

Figure 1. Painting \# 1. This figure depicts a woman from a Western perspective.

Art reflects the image of societies and includes their thoughts, cultures, and religions, and art can challenge societies to think in different ways about themselves. There seems to be a proportional relationship between the art and community. In Western culture, women have traditionally been presented in a passive way, as John Berger (1972) mentioned in his book "Ways of Seeing." Western artists have painted a woman waiting for a man, available to feed his desire anytime. She becomes nude to attract him. Grasping his attention as a passive creature, she awaits her master, to satisfy him.

In painting \# 1, I present a woman passively as a Western artist might depict her. She holds a mirror and looks at herself or looks at the viewer, waiting for his approbation as he prefers her to be nude. I surrounded her with various monuments such as the Leaning Tower of Pisa, the Eiffel Tower, and the Statue of Liberty to indicate her identity and the community to which she belongs. Although Western artists often show a woman completely naked, in my painting, I do not portray women in this way out of respect for the traditions of the Islamic religion. Moreover, I see here how her society uses art as a tool to control the woman to author her into a closed perspective without thinking about what she needs. They look at her body without thinking of her mind; they distinguish between the body and the mind by separating them into two opposite sides. I can see how the Western artist deals with women as objects without thinking about their humanity or giving them the right to decide what they want to be in their community. 


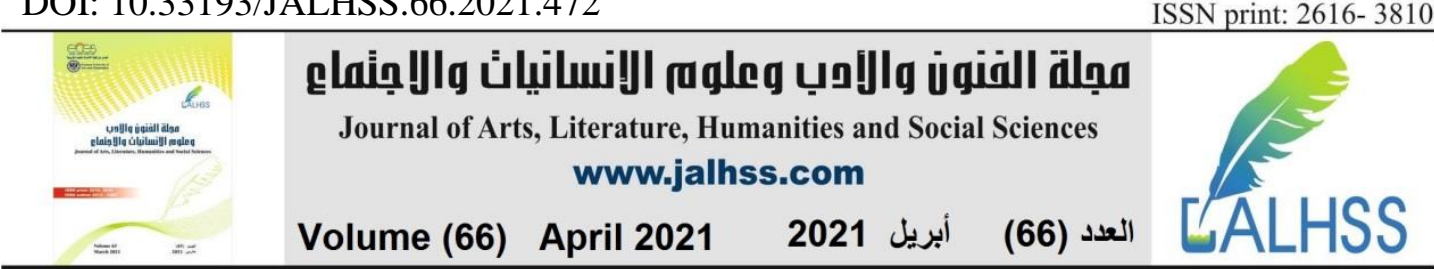

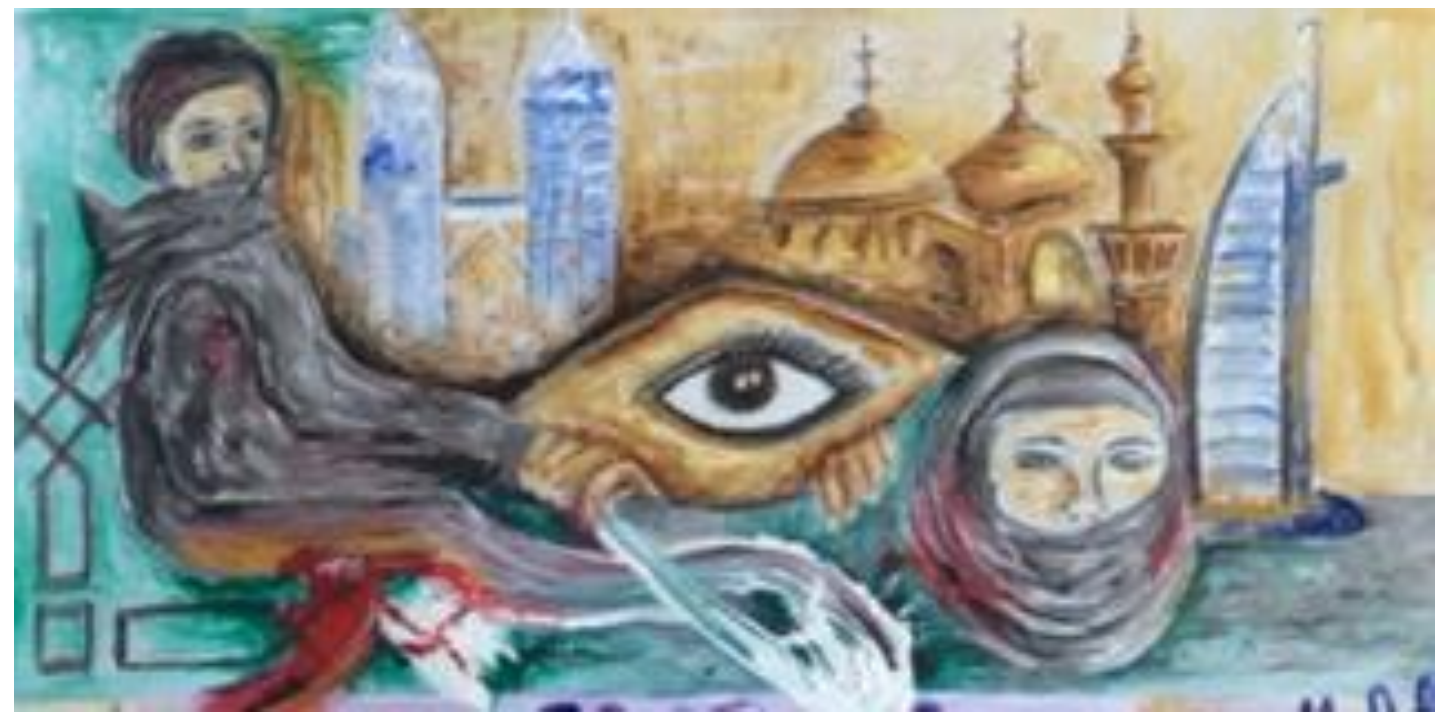

Figure 2. Painting \# 2. This figure conveys a woman from an Eastern perspective.

From another perspective, the East, despite having cultural differences from the West also presents women passively. In the Islamic world, a woman should cover her body according to the Islamic restrictions to preserve her privacy and protect herself from intruders who would break into her world. Islam is as religion of moderation, as it gives women their rights and urges respect and appreciation for women. However, some Eastern conservative cultures require women to cover their faces, wear gloves, and stay at home out of respect for the social traditions followed in these societies. Further, the conservative community advocates segregation between the genders, so there is a little interaction with members of the other gender (this sometimes depends on the specific culture). From this standpoint, my second painting portrays a woman as a prisoner of cultural and traditional aspects of her society: she does not like to look directly toward the viewers, especially men, as a kind of escape from this confrontation with the opposite sex. Just as in the previous painting, I show some features, such as the mosques, the Arab Tower in Dubai, and the Twin Tower in Malaysia to indicate the identity of the woman.

Furthermore, art challenges this perspective of presenting women passively as an object, in which she is available to the viewer as a commodity. A woman needs to understand her role in the world and what she wants to be, not merely as the society wants her to be. A woman aims to be a free, strong, active, and effective person in her community. Society controls a woman and frames her image in different ways depending on others' perspective, without giving her the right to decide who she is in the world, or what she wants. 


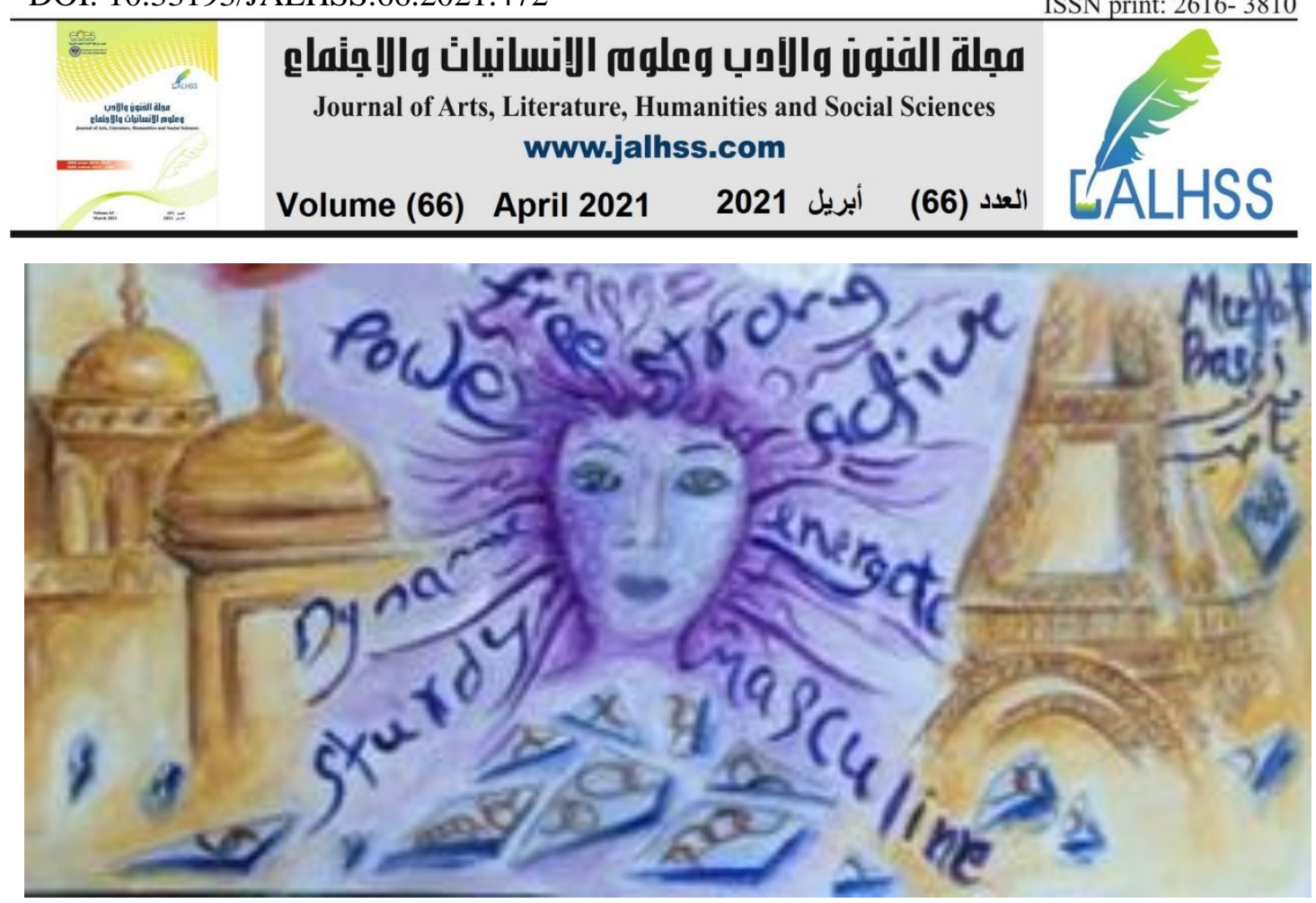

Figure 3. Painting \# 3. This figure depicts my perspective on the active woman.

For instance, in one local exhibition in Saudi Arabia, the curator of the exhibition refused to accept my painting because it portrayed a woman in a strapless dress. Unfortunately, even a female artist cannot have the freedom to present a woman as she prefers because the community refuses to accept this view. In the United States, I faced a perspective opposite to the East's view of presenting a woman. In some of my art studio classes in my Ph.D. program, I discovered it was very difficult for me to depict a nude model, ignoring my religion, culture, and beliefs on presenting a woman in this way, which led to my taking on additional assignments instead of participating in these classes.

Therefore, painting \# 3 conveys my desire for a woman to break the mirror that does not reflect her image, but rather reflects the limitations that prohibit her from being an effective individual working for the development of society. As the next point in this paper, I discuss the important role of Saudi Vision 2030, which has created a space for Saudi women, empowering them in their society to become an effective component of the service to their homeland and its development in various fields.

\section{Women in the Kingdom's 2030 Vision}

The Kingdom of Saudi Arabia has witnessed comprehensive development in many areas, such as the economic, social, and cultural fields, as a result of Vision 2030. AlRamah, Deputy Minister of Labor and Social Development, stated that the Kingdom's Vision 2030 is based on three axes: "A vibrant society, a thriving economy, and an ambitious nation" (2018, para. 1). In addition, the kingdom has focused its efforts on empowering women in various fields and enhancing their scientific, cultural, practical, and economic standing. His Royal Highness Prince Mohammed bin Salman affirmed several sustainable development goals at the High-Level Political Forum 2018, and among the most important of these goals was achieving gender equality and 


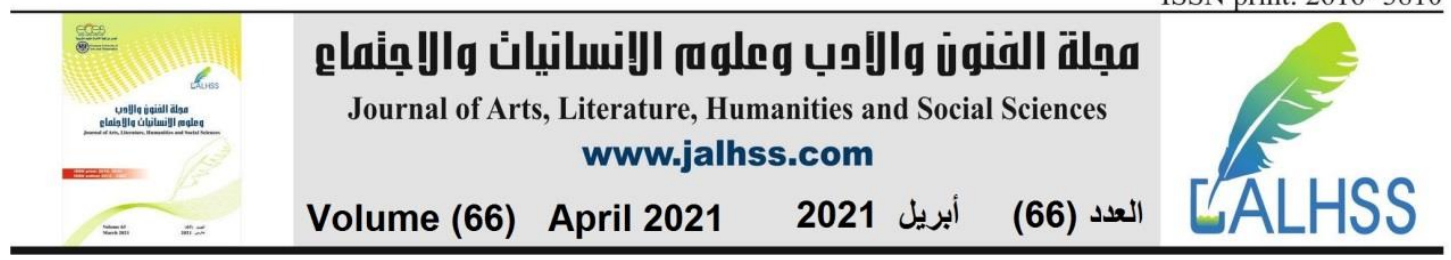

empowering all women and girls. Hence, Prince Mohammed asserted that "There is no doubt that women's work is very important, and they are half of society, and they must be effective and productive in Saudi Arabia" (2018, p. 61). Al-Dawood (2019) pointed out that Saudi women have proven their excellence in many fields, such as education, health, media, culture, economics, finance, investment, and various services.

Al-Ramah (2018) highlighted the fact that Vision 2030 expresses the role of Saudi women in their society, pointing out that

Saudi women are an important component of the Kingdom's strength, and we will continue to develop their talents, invest their energies and enable them to obtain appropriate opportunities to build their future and contribute to the development of our society and our economy. (para. 2)

Also, Al-Ramah (2018) praised the Kingdom's efforts to support women in education, as they accounted for $56 \%$ of graduates, and the number of female scholarship students studying outside the Kingdom reached 205,000.

Moreover, Al-Rabah (2018) noted the role of Saudi Arabia in supporting Saudi women and their economic independence by establishing several programs. These programs include the "التحول الوطني 2020" program that supports women's economic empowerment and increased participation in the labor market; the "قرة" program to host the children of working women; the "وصول" program for the transfer of working women; and the program to support self-employment, part-time work, and remote work. In addition, the Kingdom seeks to empower women in leadership positions, such as on the "Shura Council" and municipal councils, to achieve balance between the sexes, and to prevent wage discrimination between men and women.

The observations of Dr. Al-Rabah (2018) were made at the symposium "Women in the Kingdom's Vision 2030." According to the Saudi News Agency (SPA) (2018, December 23), Dr. Hoda Al-Helisi presented at the same symposium. In a 2018 paper entitled "Woman, Rights, and 2030 Vision," Al-Helisi referred to "the Arab and international agreements signed by the Kingdom and committed to them to protect women's rights, enable them to work, and enable them to fulfill their social role" (para. 8). Al-Helisi said that the Kingdom is committed to many Arab and international conventions, including "the convention on the elimination of all forms of discrimination against woman, and the G20's commitment to gender equality" (para. 9).

Moreover, in the Arab International Economic Newspaper, Al Mutrek (2018) reported on the efforts of the Kingdom to involve Saudi women in different fields; she stated that

In 2016, the Kingdom adopted the 'Saudi Vision 2030' and the National Transformation Program 2020, which put the empowerment of Saudi women as a priority, as the 'Vision' plan aims to raise the contribution of women in the local economy from 22 percent to 33 percent, in addition to reducing unemployment among them. (para. 17) 


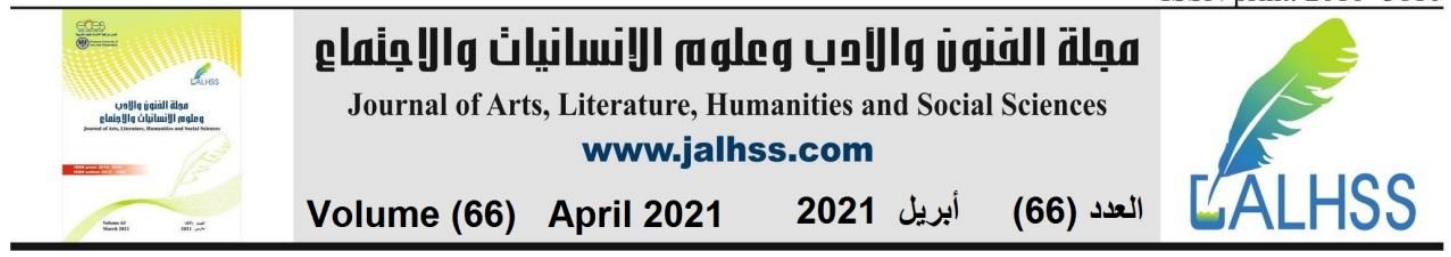

In addition to issuing decisions in support of Saudi women in several areas, including equality between men and women, their participation in the labor market, and their role on the Shura Council, King Salman bin Abdul-Aziz made the decision to issue driving licenses to Saudi women in 2017 (Al Mutrek, 2018).

In the SPA (2019, April 26), Al-Dakhil (2019) stated that the Kingdom of Saudi Arabia has been concerned with empowering women in several areas, including achieving the principle of gender equality, the right to education, and access to senior positions. In 2017, women were empowered as a result of several decisions: allowing them to drive a car, the law on harassment, allowing girls to play sports in schools, allowing women to participate in the Olympic Games, and allowing them to fly airplanes. In 2019, the first female ambassador from the Kingdom of Saudi Arabia, Princess Rima bint Bandar bin Abdul-Aziz, was appointed as ambassador to the United States of America with the rank of minister.

Moreover, the SPA (2020, July 14) reported on the statement from the General Authority for Statistics that the growth of woman's empowerment in the Saudi labor market will increase by 25 percent. Besides, woman's participation increases economic development, and the unemployment rate among females decreased during the first quarter of 2020. The Kingdom is focusing its efforts on reducing the gap in the workforce between the sexes to achieve economic balance. Also, the Kingdom supports women by establishing children's hostels in workplaces to help women demonstrate their effective role in Saudi society.

The Kingdom of Saudi Arabia and its leaders have emphasized the importance of empowering Saudi women and granting them more rights as a primary goal of the Kingdom's 2030 Vision. Ahmed Naseer (2020) pointed out the ten most important gains for Saudi woman in 2019, which are revoking male guardianship over women, canceling the requirement for travel permits from guardians, allowing women to obtain passports, appointing the first female ambassador, allowing women to enter the parliament and participate in parliamentary work, giving a mother to give notification of her newborn, giving the right of a wife to obtain her marriage certificate, making adjustments in the civil affairs law to give women their rights, and allowing women to enter sports stadiums.

Many government and private sectors agencies celebrated International Women's Day, and the role of the Kingdom of Saudi Arabia in supporting women and empowering them in various fields has been praised in light of the 2030 Vision (AlKhorayef, 2018; Al-Omani, 2020; Al-Suhail, 2019; Eatif, 2019; Jafari, 2019; Okaz, 2018; SPA, 2020, February 11; SPA, 2018, March 4). In the global arena, Saudi women have made many achievements in the scientific, functional, economic, political, health, social, artistic, and sports fields, and they have demonstrated that they have an essential role in building the family in particular and society in general (Al-Khorayef, 2018; Eatif, 2019; Okaz, 2018). On the national level, the Kingdom's Vision 2030 has focused on empowering Saudi women through encouraging their active participation in developing their society and by supporting them in the labor 


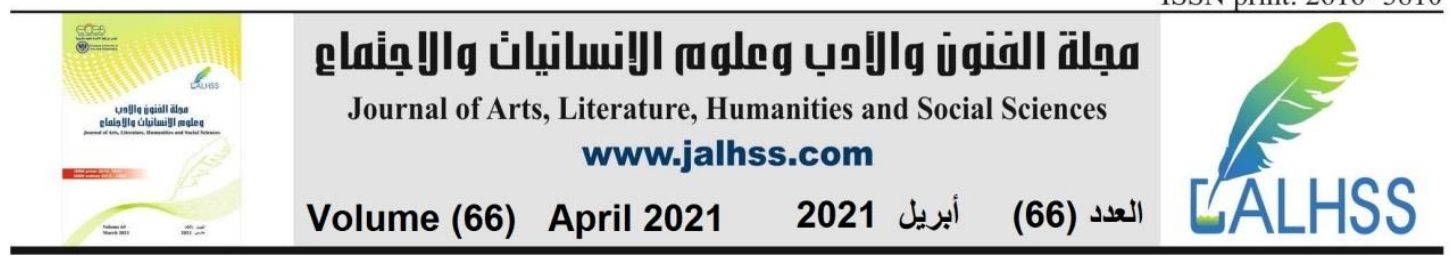

market in terms of reducing the unemployment rate (Al-Khorayef, 2018; Al-Omani, 2020; Al-Suhail, 2019; Eatif, 2019; Jafari, 2019; Okaz, 2018; Saudi Press Agency, 2020, February 11; Saudi Press Agency, 2018, March 4). Thus, Saudi women have demonstrated their presence, importance, and effective role in various fields locally, regionally, and internationally.

Several events were held to celebrate "international Women's Day" in many governmental and private sector organizations. Al-Jafari (2019) reported that some of these events were the "ثقة" event in the city of Jeddah, which aims to empower women in the labor market and activate their role in society in light of the Kingdom's 2030 Vision. According to Al-Jafari (2019), many events have been organized that highlight the effective role of Saudi women in various areas, such as political, social scientific, health, sports, economic, and educational fields. Al-Jafari (2019) listed a number of important activities: women's sports competitions under the title "Football that Brings us Together," an exhibition at King Saud University, a forum "Towards Empowering Women" with the support of the Riyadh Chamber, a marathon for walking and running for women organized by King Saud University, and the forum "Saudi women... Ambitions and Achievements in Light of the Kingdom's Vision 2030" at Taif University. In addition, many organizations celebrated International Women's Day; these include Saudi Aramco, the Saudi Telecom Company, and the Public Prosecution in Saudi Arabia, as Al-Jafari (2019) reported.

Furthermore, the SPA (2020, February 11) reported out that the King Abdul-Aziz Center for National Dialogue organized various activities on International Women's Day 2020, including an exhibition of plastic art, photography, handicrafts, and artistic talents. Also, the center established a library, a cultural evening, and documentary films about the achievements of Saudi women, as the SPA (2020, February 11) reported. In addition to the achievements of Saudi women in the artistic field, the SPA (2018, March 4) indicated that they have also distinguished themselves in the scientific fields and have made many scientific accomplishments and advancements at the local and international levels.

Many names of Saudi female scientists and researchers have shone in several fields (Eatif, 2019; Okaz, 2018; SPA, 2020, February 11). For example, Okaz newspaper (2018) reported on the role of Saudi women in various significant fields such as the political, scientific, arts, engineering, sports, health, and space fields. Also, Eatif (2019) showed that Saudi women have made effective achievements in the field of sound and magnetic waves and the field of medicine. Finally, the SPA (2020, February 11) pointed out that Saudi women have been distinguished in several areas, including the medical, scientific, technological, chemistry, physics, mathematics, and oil fields.

\section{Conclusion}

The main point of this study has been to highlight the importance of the Kingdom's 2030 Vision in supporting Saudi women and empowering them to develop their 


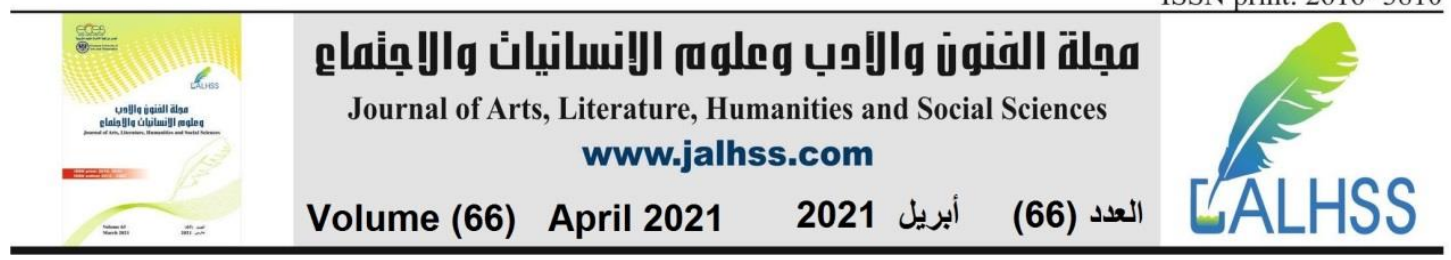

society and author themselves in different areas, such as the educational, political, economic, social, and cultural fields. In this paper, I emphasized how offering a space of dialogue for women from the Middle East to author themselves in an alternative world can help women develop their identities by using different solutions/possibilities in order to deal with social and cultural restrictions. I made the practical decision to focus on women from the Middle East because they are from the minority group and need some support to possess their agency and voice in order to understand themselves and who they are in the world.

In this paper, first, I presented background information on the social positions of women in the figured worlds and what some obstacles that they encounter are. I identified the important role of the culture to understand the social positions of ourselves and other individuals in the figured worlds. More specifically, I focused on how women practice their identities in figured worlds and how they use artifacts to help themselves to engage in their worlds. Also, I focused on the relationship between the self and others - women and society - which is important for obtaining a clear view of our/their social identities. Women still suffer every day of their lives, as a minority group whose members demand their rights and try to find their agency in the alternative world.

I then provided examples of various possibilities for women to make a space of dialogue, as a kind of artifact, to help themselves practice their identity. I focused on some of these artifacts that support women in their figured worlds to engage in the alternative/imagined worlds; some of these artifacts involve dancing/singing, artworks, and women's bodies. These activities are important ways for women to convey their mission to the world. Also, I demonstrated how these possibilities/solutions could help women to deal with social and cultural constraints in expressing who they are and developing their identities. I concluded this part of my paper with a strong recommendation that women should keep fighting to convey their message to the world and finding other solutions/possibilities that help them to develop their identity.

In a personal visual reflection, I tried to find a solution by making art; I portrayed a woman struggling between two different worlds - East and West. Through these artworks (my paintings), I wanted to show the power of art in its use as a tool (artifact) to establish an effective dialogue between society and individuals, especially women. Also, I wanted to provide a space for a woman to express herself by understanding who she is in society and the positive role she plays in building her society. Finally, I concluded this paper by exploring the importance of the 2030 Vision for Saudi women wishing to develop their society and author themselves in different fields. Thus, Vision 2030, under the leadership of Prince Mohammed bin Salman, has supported Saudi women, as they are half of society and an important part of this great edifice, who have capabilities and skills that will help the Saudi society to grow and prosper. 


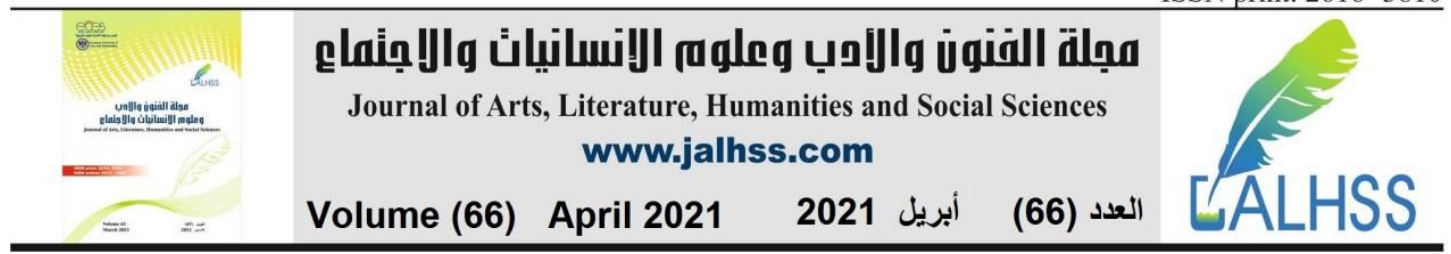

\section{References}

1. Al-Dawood, A. (2019, January 9). تمكين العرأة في رؤية 2030 [Empowering women in Vision 2030]. Retrieved from https://www.alriyadh.com/1730345

2. Al-Khorayef, R. (2018, March 11). المرأة السعودية في اليوم العالمي للهرأة [Saudi women on International Women's Day]. Retrieved from https://www.aleqt.com/2018/03/11/article_1347581.html

3. Al Mutrek, N. (2018, September 23). "المرأة في "عه الرؤية" .. قدرة وجدارة على تعزيز [Women in "era of vision" .. the ability and merit to strengthen the development map]. Retrieved from https://www.aleqt.com/2018/09/23/article_1458701.html

4. Al-Omani, F. (2020, March 4). اليوم العالمي للمراة السعودية/International Saudi Women's Day]. Retrieved from https://www.alarabiya.net/amp/sauditoday/views/2020/03/04

5. Al-Suhail, K. (2019, April 1). بوم العرأة السعودية [Saudi Women's Day]. Retrieved from https://www.aleqt.com/2019/04/01/article_1571821.html

6. Berger, J. (1972). Ways of seeing. U.K: Penguin Books.

7. Crenshaw, K. (2015, September 24). Why intersectionality can't wait. The Washington Post.

8. Dieudonne, S., \& Scherbel-Ball, N. (2016). 100 women 2016: Female Arab cartoonists challenge authority. $B B C$ News. Retrieved from http://www.bbc.com/news/world-middle-east-38103902

9. Eatif, M. (2019, March 8). في اليوم العالمي للمرأة (2019) . السعوديات بؤكن ريادتهن [On International Women's Day (2019).. Saudi women confirm their leadership]. Retrieved from https://sabq.org/dRFcTk

10. Holland, D., Lachicotte, W., Skinner, D., \& Cain, C. (1998). The women who climbed up the house. In A. B. Smith (Ed.), Identity and agency in cultural worlds (pp. 3-18). Cambridge, MA: Harvard University Press.

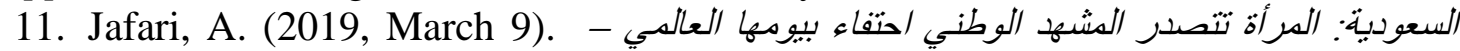
] حزمة فعاليات عززت دورها و استعرضت إنجاز/تها of the national scene to celebrate their International Day - a package of events that enhanced their role and showcased their achievements]. Retrieved from https://aawsat.com/home/article

12. Merino, A. (2015). The female body and identity: Four artists from body \& soul: New international ceramics $\backslash$ museum of arts and design. Visual Culture \& Gender, 10.

13. Naseer, A. (2020, July 5). تمكين المرأة في السعودية .. مقاعد قبادية بقطار التندية 2030 [Empowering women in Saudi Arabia.. leadership seats in the 2030 development train]. Retrieved from https://al-ain.com/article/empowering-women-ksa

14. Okaz. (2018, March 8). المرأة السعودية.. في بومها العالمي إنجاز و نجاح/ال [Saudi women.. on their international day, achievement and success]. Retrieved from https://www.okaz.com.sa/last-stop/na/1621801 


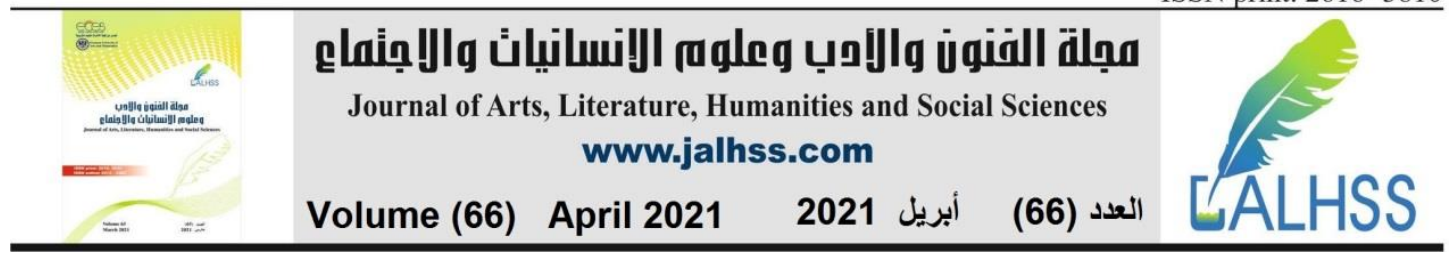

15. Rowsell, J., Kress, G., \& Street, B. (2013). Visual optics: Interpreting body art, three ways. Visual Communication, 12(1), 97-122.

16. Saudi Press Agency. (2018, March 4). مركز الملك عبد العزيز للحوار الوطني بنظم فعاليات 2020 اليوم العالمي للمرأة International Women's Day 2020 activities]. Retrieved from https://www.spa.gov.sa/2042728

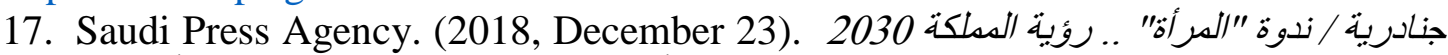
[Al-Janadriyah / “women” symposium.. The Kingdom's Vision 2030 gave special attention to the employment of Saudi women]. Retrieved from https://www.spa.gov.sa

18. Saudi Press Agency. (2019, April 26). "المرأة السعودية" تسبر بطموح و تمكبن في رؤية 2030 ["Saudi women" march with ambition and empowerment in Vision 2030]. Retrieved from https://www.spa.gov.sa/1917425

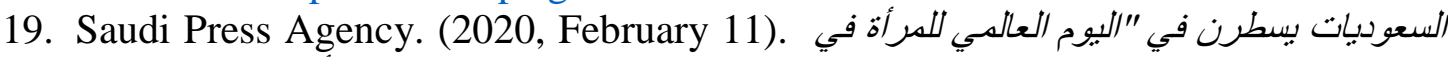
] Saudi women highlight on “International Women's Day in the field of science" their most prominent scientific achievements]. Retrieved from https://www.spa.gov.sa/viewfullstory.php?newsid=2033139

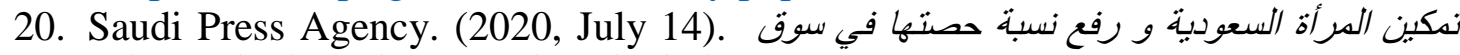
Empowering Saudi women and increasing their share in the labor market, reducing the gender gap between the workforce]. Retrieved from https://www.spa.gov.sa/viewfullstory.php?newsid=2110032

21. Sfard, A., \& Prusak, A. (2005). Telling identities: In search of an analytic tool for investigating learning as a culturally shaped activity. Educational Researcher, 34(4), $14-22$.

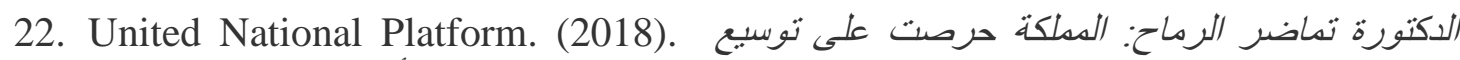
[Dr. Tamader Al-Ramah: The Kingdom is keen to expand the participation of women in all areas of development]. Retrieved from https://www.my.gov.sa/wps/portal/snp/pages/news/newsDetails/CONT-news715032018

23. Voloshinov. (1929/73). Verbal interaction. Marxism and the philosophy of language. New York: Seminar Press. 